\title{
EVIDENCIAÇÃO VOLUNTÁRIA DO CAPITAL INTELECTUAL DE NATUREZA SOCIAL E AMBIENTAL DA EMPRESA NATURA COSMÉTICOS S.A. NO PERÍODO ENTRE 2003 E 2008
}

\section{RESUMO}

O presente artigo apresenta um estudo longitudinal sobre a evidenciação voluntária do Capital Intelectual $(\mathrm{CI})$ de natureza social e ambiental nos Relatórios Anuais (RAs) da Empresa Natura Cosméticos S.A., referentes ao período entre 2003 e 2008. A pesquisa é de natureza descritiva, adota a análise do conteúdo, e segue o procedimento metodológico de abordagem qualitativa na utilização dos dados de fonte secundária. Foi utilizada a matriz de elementos de Capital Intelectual de origem social e ambiental elaborada por Silva (2008). Os resultados apontam que há uma maior tendência de evidenciação dos elementos de natureza social; que a categoria Estrutura Interna foi a mais evidenciada na área social e na área ambiental; que existe uma grande evidenciação voluntária, uma vez que dos 38 elementos investigados somente três não foram evidenciados; que há uma sutil variação na evidenciação voluntária dos elementos de natureza social ao longo dos últimos seis anos, sendo inexistente a variação no que diz respeito aos elementos de natureza ambiental.

Palavras-chaves: Evidenciação voluntária. Capital Intelectual. Responsabilidade Socioambiental. Relatórios Anuais.

\section{ABSTRACT}

This article presents a longitudinal study on the voluntary disclosure of Intellectual Capital (IC) of a social and environmental annual reports (ARs), the period from 2003 to 2008, the Company Natura Cosmetics SA This study was descriptive, content analysis takes; research is qualitative data and use of secondary source. In the study, we used the matrix elements of Intellectual Capital of social and environmental origin developed by Silva (2008). The results indicate that there is a greater tendency of highlighting the elements of a social nature and the Internal Structure category was the most evident in the social field and environmental area, there is a large voluntary disclosure because of the 38 elements investigated, only three elements were not verified, there is a subtle variation in voluntary disclosure of the elements of a social nature over the past six years, and nonexistent with regard to the environmental elements.

Keywords: Voluntary disclosure. Intellectual Capital. Socio-environmental responsibility. Annual Reports.
Bruna Matos

Donizete Reina
Mestre em Contabilidade pela
UFSC

Especialização em Controladoria e Gerência Financeira pela FCV dreina2@hotmail.com

Sandra Rolim Ensslin

Doutorado em Engenharia de Produção pela UFSC

Professor adjunto da Universidade do Sul de Santa Catarina - UNISUL sensslin@gmail.com

Diane Rossi Maximiano

Reina

Mestranda em Contabilidade pela UFSC

Especialização em Gerenciamento de Micro e Pequenas Empresas pela UFLA dianereina@hotmail.com

Recebido em 11/agosto/2009 Aprovado em 27/junho/2011 


\section{INTRODUÇÃO}

A evidenciação do valor das empresas por meio das tradicionais perspectivas tangíveis, de capital físico e capital financeiro, apresenta-se limitativa diante das atuais exigências competitivas impostas às organizações, cujos componentes formadores de valor não são observados em sua integridade, como o Capital Intelectual (KLEIN, 1998).

Sobre essa visualização restrita decorrente da evidenciação de natureza tangível, Edvinsson e Malone (1998) enfatizam uma preocupação diante da defasagem das informações apresentadas pelos demonstrativos contábeis voltados para a evidenciação tangível, identificando outro tipo de capital de natureza intangível ou invisível, o Capital Intelectual. Assim, o Capital Intelectual, juntamente com o capital físico e financeiro, compõem, na atualidade, o capital de uma organização (BRENNAN, 2001; CHEN GOH, PHENG LIM, 2004; ENSSLIN, CARVALHO, 2007).

O Capital Intelectual (CI) tem assumido papel importante na vida das pessoas e das organizações (STEWART, 1998; REZENDE, 2001; ANTUNES e MARTINS, 2007), além de produzir ativos de alto valor para as empresas (ROCHA e ARRUDA, 2005; e CUNHA 2006). Segundo Edvinson e Malone (1998, p. 40), o conceito de Capital Intelectual (CI) está relacionado aos seguintes fatores: posse de conhecimento, experiência aplicada, tecnologia, organizacional, relacionamento com os clientes e habilidades profissionais que propiciem uma vantagem competitiva para o mercado.

Para Kaplan e Norton (2004), essa vantagem competitiva, originada por meio da gestão estratégica dos ativos intangíveis, pode ser responsável em média por $75 \%$ do valor de mercado de uma empresa. Observese que, na literatura, a terminologia Capital Intelectual (CI) tem sido utilizada, intercambiavelmente, com a terminologia Ativo Intangível (AI). Entretanto, observase uma tendência de se empregar o termo AI, quando a pesquisa focaliza a Contabilidade Financeira, e de se de se usar CI no momento em que a pesquisa volta a atenção para a Contabilidade Gerencial. Portanto, esta pesquisa adotará a terminologia Capital Intelectual (CI), uma vez que aborda questões de cunho gerencial.

Entre as inúmeras possibilidades de utilização dos elementos formadores de Capital Intelectual dentro do gerenciamento estratégico das entidadesentidades destaca-se o aproveitamento deles como um mecanismo eficiente de gestão e evidenciação de ações ligadas à Responsabilidade Socioambiental (RSA), uma vez que eles permitem a identificação, a correlação e a posterior prestação de contas em relação à postura das entidades perante a sociedade.

Segundo Ashley (2005), a observação das questões relacionadas à postura responsável por meio das perspectivas sociais e ambientais apresenta-se como uma das preocupações centrais para as organizações que almejem crescer em harmonia com a sociedade e a natureza. Filho (2007) identifica o exercício da Responsabilidade Socioambiental (RSA) como um elemento que se apresenta no centro da esfera de governo da organização, em que a adoção da postura da sustentabilidade, ligada à vontade da preservação do meio ambiente no âmbito interno da organização, pode impulsionar o desenvolvimento na esfera macrossocial.

Os autores do presente artigo argumentam que as práticas de Responsabilidade Socioambiental agregam valores muitas vezes invisíveis, e que a observação delas apenas pelos enfoques financeiros e físicos não consegue representar com fidelidade os resultados decorrentes dessas ações. Portanto, a abordagem do Capital Intelectual reuniria um conjunto de fatores que permitiriam a evidenciação dos elementos relacionados com a RSA, tal como a possibilidade de uma abordagem qualitativa e de reconhecimento de componentes os quais, apesar de não serem visíveis, agregam valor à entidade.

Diante da importância da evidenciação das informações dos elementos de CI relacionados às práticas de Responsabilidade Socioambiental, este estudo visa responder a seguinte pergunta de pesquisa: qual é o comportamento da empresa Natura Cosméticos em relação à evidenciação voluntária de seu Capital Intelectual de natureza social e ambiental? A escolha pela empresa Natura Cosméticos ocorreu pelo fato de essa empresa ter uma postura socialmente responsável, que busca relacionar sua marca às ações socioambientais e enfatiza o termo sustentabilidade. O objetivo principal de responder a pergunta de pesquisa consiste em analisar a evidenciação voluntária dos elementos do Capital Intelectual de natureza social e ambiental constantes nos Relatórios Anuais (RAs) da Empresa Natura Cosméticos S.A., no período entre 2003 e 2008. Para o alcance do objetivo geral, têm-se como objetivos específicos: (i) identificar os elementos e as categorias do CI que são evidenciados voluntariamente nos RAs da empresa Natura Cosméticos, nos anos 2003, 2004, 2005, 2006, 2007 e 2008, por meio da análise de conteúdo; (ii) comparar longitudinalmente os resultados da evidenciação do Capital Intelectual; (iii) coletar manifestações/depoimentos que reconhecem a presença dos recursos intangíveis.

A presente pesquisa está estruturada em cinco seções. Esta primeira seção, de caráter introdutório, aponta, entre outros itens, os objetivos do trabalho; a segunda, apresenta a fundamentação teórica; a terceira, traz a metodologia da pesquisa; a quarta, exibe a discussão sobre os resultados encontrados, e a quinta seção expõe as considerações finais, que são seguidas das referências.

\section{FUNDAMENTAÇÃO TEÓRICA}

Esta seção apresenta o embasamento teórico que deu suporte ao desenvolvimento da presente pesquisa e que 
foi dividido em três partes. A primeira parte oferece uma breve conceituação a respeito de Capital Intelectual (CI); a segunda contempla a evidenciação voluntária do CI e a terceira parte aborda as perspectivas de Responsabilidade Sócio-Ambiental adotadas neste estudo.

\subsection{Capital Intelectual}

Os termos Ativo Intangível e Capital Intelectual (CI) são muitas vezes utilizados como sinônimos (GALLON, LYRIO, ENSSLIN, 2008) e, segundo Zanini e Calvo (2006), isso não representa um erro, embora para os autores, a expressão CI seja um conceito mais geral, e ativo intangível mais restrito.

De acordo com Feiwal (1976 apud BONTIS, 1998), o termo capital intelectual foi publicado pela primeira vez por John Kenneth Galbraith em 1969, o que acreditava que o CI incorporava uma ação intelectual, sendo muito mais do que um intelecto puramente. Nesse sentido, o CI não representaria somente uma noção estática de ativo intangível, mas, sim um processo ideológico, uma via para atingir um fim (BONTIS, 1998).

Segundo Edvinson e Malone, (1998 apud GALLON, LYRIO, ENSSLIN, 2008) o conceito de CI está relacionado aos fatores: posse de conhecimento, experiência aplicada, tecnologia, organizacional, relacionamento com os clientes; e habilidades profissionais que propiciem uma vantagem competitiva para o mercado.

Com relação aos elementos que formam o CI, não se encontra na literatura uma classificação unânime. Tem sido evidenciado um grande número deles, a exemplo dos que constam na classificação adotada por Sveiby (1998), a qual aponta três grupos denominados: (a) Competência do Funcionário, que envolve capacidade de ação em diversas situações para criar tanto ativos tangíveis como intangíveis; (b) Estrutura Interna, a qual inclui patentes, conceitos, modelos e sistemas administrativos e de computadores, enfim, toda a estrutura organizacional, e (c) Estrutura Externa, que abrange relações com os clientes e fornecedores, bem como marcas, marcas registradas e a reputação ou a imagem da empresa.

\subsection{Evidenciação Voluntária do CI}

As evidenciações voluntárias são meios utilizados pelos investidores para analisar as estratégias e os fatores críticos de sucesso da companhia, tanto no ambiente em que as mesmas estão inseridas como sob o aspecto competitivo de cenário econômico (PIACENTINI, 2004).

Como resultado, uma tendência tem se manifestado: as informações sobre as práticas de CI são divulgadas voluntariamente, de tal forma a preencher esse espaço (MOUTISEN, BUKH e MARR, 2005) e a reduzir a assimetria informacional (IUDÍCIBUS, 2004). A partir dessa constatação, destaca-se a necessidade de redução da assimetria informacional, por meio da evidenciação. Segundo Iudícibus e Lopes (2004) e Lopes e Martins (2005), uma consequência dessa divulgação voluntária é a produção de um impacto no preço das ações. $\mathrm{Na}$ tentativa de atender a esse mercado e, consequentemente, melhorar o valor de suas ações e atrair possíveis futuros investidores, as empresas estão identificando e divulgando os elementos que compõem o seu CI.

Para Moutisen, Bukh e Marr (2005 apud REINA e ENSSLIN, 2008), existem alguns motivos que justificam uma necessidade crescente em relatar informações sobre CI. Um desses motivos é que tais informações - se não divulgadas - podem prejudicar os acionistas minoritários, uma vez que eles não possuem livre acesso aos intangíveis das empresas. Outro motivo seria o acesso a informações "privilegiadas", o que pode, eventualmente, gerar um "comércio" dessas informações entre os gestores, com o intuito de explorá-las. Um terceiro motivo apontado pelos autores é a liquidez do mercado de ações e a busca crescente pelos títulos de crédito oriundos de empresas com uma maior divulgação voluntária desses intangíveis. Um quarto motivo é o perigo de geração de estimativas imprecisas para os investidores e demais stakeholders, no caso de não divulgação do CI. Um quinto e último motivo está relacionado ao aumento no custo de capital, em razão do maior grau de risco imputado às empresas.

\subsection{Responsabilidade Socioambiental}

A observação das questões relacionadas à postura responsável por meio das perspectivas sociais e ambientais apresenta-se como uma das preocupações centrais para as organizações que almejem crescer em harmonia com a sociedade e a natureza (ASHLEY, 2005).

Filho(2007)identificaoexercíciodaResponsabilidade Sócio-Ambiental como um elemento que se revela no centro da esfera de governo da organização, em que a adoção da postura da sustentabilidade, ligada à vontade da preservação do meio ambiente no âmbito interno da organização pode impulsionar o desenvolvimento no âmbito macrossocial.

Para Ashley (2005), os fins sociais relacionam-se ao propósito das empresas de adotar uma postura voltada às questões éticas, de cidadania, bem-estar, responsabilidade social e ambiental.

Ser socialmente responsável implica, para a empresa, valorizar seus empregados, respeitar os direitos dos acionistas, manter relações de boa conduta com seus clientes e fornecedores, manter ou apoiar programas de preservação ambiental, atender à legislação pertinente à sua atividade, recolher impostos, apoiar ou manter ações que visem diminuir ou eliminar problemas sociais nas áreas de saúde e educação e fornecer informações 
sobre sua atividade. Em resumo, a empresa deve ter os conceitos de ética e transparência como os princípios de sua conduta. (ASHLEY, 2005, p. 173).

Muitos são os fatores que podem agir sobre as organizações a ponto de despertar-lhes a motivação para desenvolver ações socialmente responsáveis. Ashley (2005, p. 71) apresenta o seguinte fator, como principal encorajamento para que as empresas assumam uma postura socialmente responsável.

O principal motivo para uma empresa ser socialmente responsável é que isso proporciona a ela consciência de si mesma e de suas intenções na sociedade. Em um mundo em que a realidade de mercado muda com uma velocidade cada vez maior, a empresa precisa saber exatamente qual é a sua missão, e a busca de um sentido ético para sua existência deve voltar-se tanto às relações de mercado quanto às relações além de mercado.

Para a avaliação do desempenho social e ambiental, a empresa Natura adota os modelos preconizados pelo Instituto Ethos de Empresas e Responsabilidade Social e pela Global Reporting Initiative (GRI). O Instituto Ethos, fundado em 1998, tem como objetivo mobilizar e apoiar empresas a conduzirem seus negócios de forma socialmente responsável. A GRI, surgida em 1997, é produto do esforço de instituições multilaterais para desenvolver uma estrutura de relatórios espontâneos sobre o impacto econômico, social e ambiental das atividades de empresas. A Natura integra o Structured Feedback Group, fórum de 30 grandes corporações internacionais que adotaram o modelo GRI em seus relatórios e é a única empresa brasileira, reconhecida pela GRI, a adotar integralmente o seu modelo.

\section{METODOLOGIA}

Nesta seção, apresenta-se o enquadramento metodológico da pesquisa, a técnica utilizada para verificação da evidenciação voluntária dos elementos de natureza social e ambiental nos Relatórios Anuais da Natura: a técnica de "análise de conteúdo", a fonte de coleta de dados e os procedimentos para registro e análise dos dados da pesquisa.

\subsection{Enquadramento Metodológico}

Este estudo tem caráter descritivo, visto que investiga as formas de divulgação dos elementos de Capital Intelectual nos Relatórios Anuais (RA). Para Andrade (2002 apud Beuren, 2003, p. 81) o estudo descritivo preocupa-se em "[...] observar os fatos, registrá-los, classificá-los e interpretá-los".

A pesquisa se insere na abordagem qualitativa, pois a análise realizada procura identificar os elementos de CI de natureza social e ambiental; logo, não se vale de instrumentos estatísticos na coleta e análise dos dados (RICHARDSON, 1999). A realização do estudo envolveu a leitura e interpretação dos dados contidos nos RAs.

A fonte de investigação utilizada no estudo são de origem secundária (RICHARDSON, 1999), uma vez que os dados são extraídos dos RAs da empresa pesquisada.

$\mathrm{O}$ procedimento técnico empregado baseou-se na pesquisa documental, já que a análise dos RAs apresentase como fonte para a posterior identificação dos elementos de CI de natureza Social e Ambiental evidenciados pela empresa integrante da amostra. Na visão de Richardson (1999, p. 253), esse tipo de pesquisa “[...] não tem relação direta com o acontecimento registrado, senão através do elemento intermediário [...]", neste caso, os RAs.

\footnotetext{
A pesquisa documental corresponde a toda informação de forma oral, escrita ou visualizada. Ela consiste na coleta, classificação, seleção difusa e utilização de toda espécie de informações, compreendendo também as técnicas e os métodos que facilitam a sua busca e a sua identificação (FACHIN, 2005, p. 136).
}

Para realizar a coleta e interpretação dos dados nos relatórios, foi utilizada a técnica da análise de conteúdo. Bardin (2004, p. 34) afirma que "[...] a intenção da análise de conteúdo é a inferência de conhecimentos relativos às condições de produção (ou eventualmente recepção), inferência essa que recorre a indicadores (quantitativos ou não)". No caso do presente estudo, a inferência se dará pela identificação de elementos cuja representatividade será obtida por meio das frequências de evidenciação.

Puglisi e Franco (2005) afirmam que para se proceder à análise de conteúdo deve-se, necessariamente , identificar a unidade de registro que se irá investigar. Essa identificação “[...] é indispensável para a necessária análise e interpretação dos textos a serem decodificados [...] e, principalmente, para que se possa estabelecer a necessária diferenciação resultante dos conceitos de significado e sentido" (ibid, p. 43). Neste artigo, a 
unidade de registro utilizada foi a sentença. Sendo assim, as sentenças dos RAs lidas, e a mensagem, quando estava vinculada a um dos elementos integrantes das Tabelas $1 \mathrm{e}$ 2, foi incluída na pesquisa, assim como na evidenciação de depoimentos/manifestações sobre a importância dos recursos intangíveis.

Para a condução deste estudo, foi utilizada a nomenclatura do modelo de classificação de capital intelectual (CI) proposto por Sveiby (1997), a matriz de elementos de CI de origem social e ambiental elaborada por Silva (2008) e a codificação numérica proposta por Guthrie et al (1999).

A pesquisa tem como limitação o período de análise do conteúdo. A principio seriam analisados os RAs do período 2000-2008, mas, como a empresa investigada não disponibilizou em tempo hábil os RAs de 2000 , 2001 e 2002, este artigo ficará limitado ao período entre 2003 e 2008. A escolha da Natura Cosméticos deveu-se à postura da empresa de ser socialmente responsável e de visar à sustentabilidade na sua gestão, o que corrobora a relevância do estudo. A investigação adota uma perspectiva longitudinal, buscando encontrar correlações entre variáveis por meio de observações repetidas dos mesmos itens ao longo de um período de tempo.

\subsection{Procedimentos para coleta e análise dos dados}

Para o alcance do objetivo deste artigo, a evidenciação das informações relativas aos elementos de Capital
Intelectual de natureza social e ambiental foi desenvolvida com base na metodologia de Guthrie et al. (1999 apud CARVALHO, ENSSLIN, IGARASHI, 2006). Os autores utilizaram um sistema de quatro códigos numéricos:

0 = Item não apareceu no relatório anual;

$1=$ Item apareceu no relatório anual em forma narrativa;

2 = Item recebeu um valor numérico no relatório anual;

$3=$ Item recebeu um valor monetário no relatório anual.

Para o registro e posterior tabulação dos dados, foi empregada somente a nomenclatura de classificação de Sveiby (1998 apud CARVALHO, ENSSLIN, IGARASHI, 2006) no que diz respeito às três categorias: Competência dos Funcionários, Estrutura Interna e Estrutura Externa. Foram utilizadas também duas tabelas como matrizes elaboradas por Silva (2008) que contemplam a perspectiva do CI sob a ótica da Responsabilidade Social e Ambiental. A primeira matriz contempla a perspectiva de Capital Intelectual de origem Social e a segunda leva em consideração a perspectiva de Capital Intelectual de origem Ambiental.

\section{APRESENTAÇÃO E DISCUSSÃO DOS RESULTADOS}

A pesquisa tem como foco identificar a evidenciação voluntária dos elementos que compõe o CI de natureza social e ambiental nos Relatórios Anuais da Natura

Tabela 1: Matriz de elementos de CI de natureza social

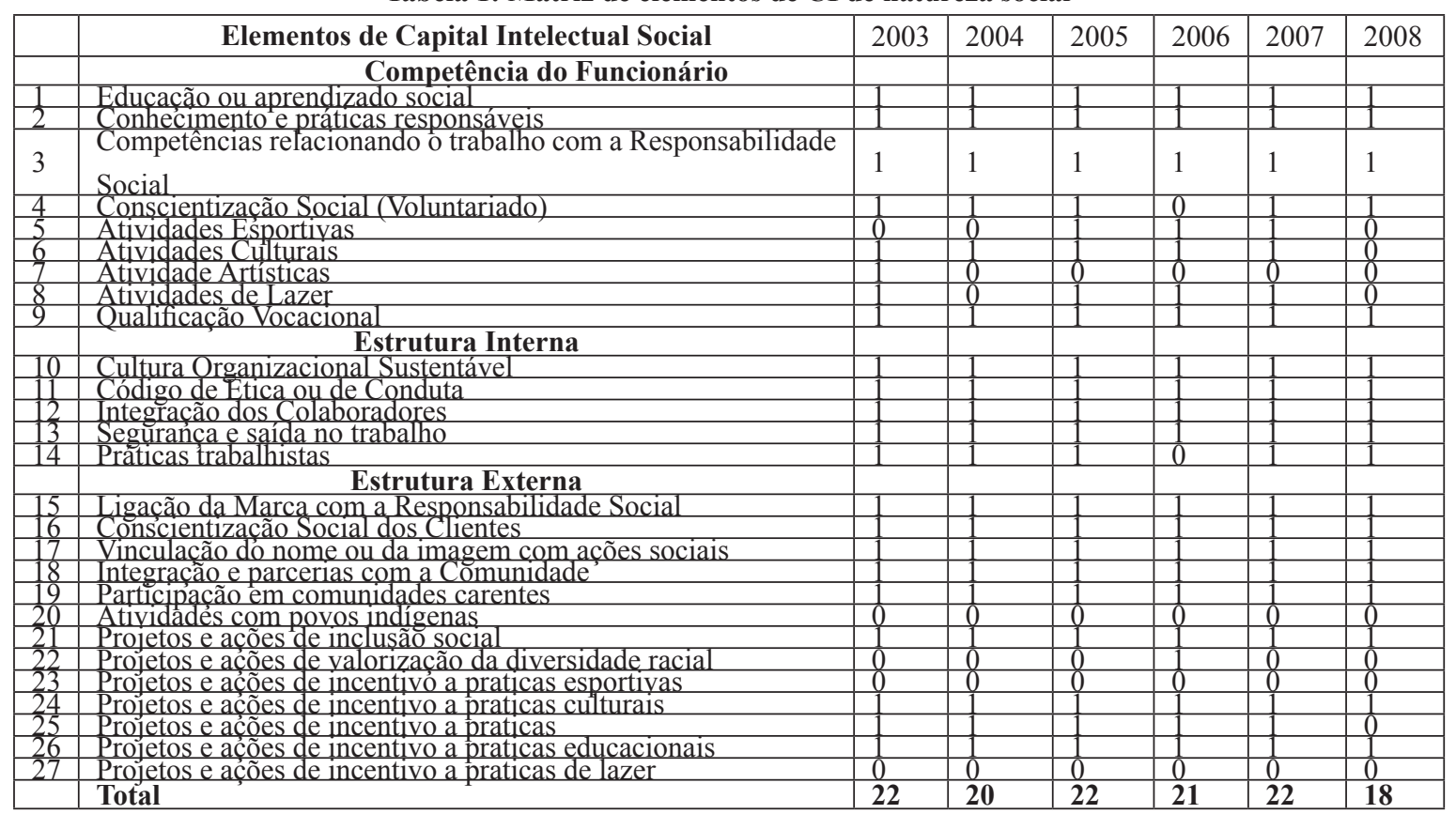

Fonte: Silva, 2008. 
Cosméticos, no período entre 2003 e 2008, bem com a evidenciação de depoimentos/manifestações sobre a importância dos recursos intangíveis.

\subsection{Identificação dos elementos e das categorias do CI}

Esta seção do expõe as análises realizadas para a obtenção das frequências de evidenciação dos elementos de CI de natureza social e ambiental da empresa investigada, utilizando o modelo de codificação numérica proposto por Guthrie et al (1999), uma matriz de elementos de CI de origem social e outra ambiental, elaboradas por Silva (2008), subdivididas de acordo com a nomenclaturas de capital intelectual (CI) proposta por Sveiby (1997).

\subsubsection{Evidenciação dos elementos e das categorias do CI de natureza social}

A matriz de elementos sociais está subdividida em três categorias que compõem o CI, distribuídos da seguinte forma: nove elementos na Competência do Funcionário, cinco na Estrutura Interna e 13 elementos na Estrutura Externa, perfazendo um total de 27 elementos, conforme Tabela 1.

Após a análise das evidenciações, os dados foram organizados em forma de gráfico, como uma maneira de melhor visualizar se houve ou não uma evolução ao longo do período de acordo com as respectivas categorias. seis anos foi a Estrutura Interna, que confirma o modo pela qual a empresa Natura vem sendo administrada, dando ênfase a fatores como cultura organizacional, código de ética e conduta, integração dos colaboradores, segurança e saúde no trabalho e práticas trabalhistas, com ações de dentro para fora da organização.

Gráfico 2 - Evidenciação dos elementos de CI de natureza social

\section{Evidenciação de Elementos de $\mathrm{Cl}$ de Natureza Social}

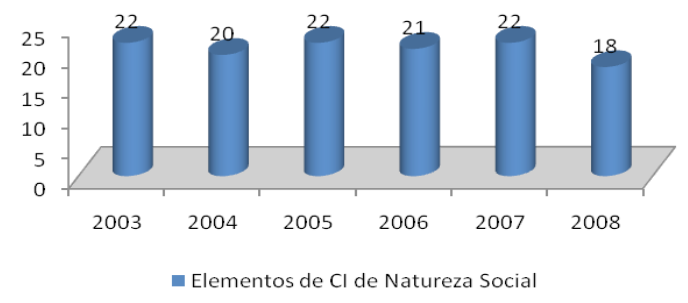

Fonte: Elaboração própria.

No Gráfico 2 é demonstrada uma suposta evolução com relação aos 27 elementos propostos neste estudo. Percebe-se que não houve uma evolução representativa quanto à evidenciação dos elementos. Por mais que tenha havido uma evidenciação significativa dos elementos de CI desde o ano de 2003, a empresa não se mostrou preocupada em evidenciar, ao longo do período, elementos diferentes dos que já havia evidenciado em relatórios anuais anteriores, e sim enfatizar cada vez mais os elementos já mencionados. Isso indica a falta de preocupação da empresa analisada em evoluir nas suas evidenciações.

É possível perceber que no RA de 2008 houve uma redução de evidenciações de CI de natureza social. A empresa procurou abordar questões até então não referidas em relatórios anteriores. Acredita-se que a crise econômico-financeira mundial tenha interferido na elaboração desse relatório, direcionando sua maneira de tratar assuntos de natureza econômica

Conforme mostrado no Gráfico 1, o número de elementos evidenciados voluntariamente é considerado significativo, porém, não houve uma evolução significativa. A categoria mais evidenciada ao longo dos e financeira. Pode-se talvez caracterizar o relatório de 2008 como um fato isolado; por isso, seria necessária/ interessante a continuação deste estudo.

Todos os elementos evidenciados foram classificados 
de forma narrativa. Para ilustrar algumas evidenciações, a seguir serão reproduzidos trechos referentes às informações retiradas dos RAs da empresa Natura Cosméticos.

Com o intuito de facilitar a identificação dos elementos, nos exemplos abaixo, as palavras-chaves serão destacadas em negrito e itálico.

Durante a leitura dos Relatórios, fica nítida a preocupação da Natura com a qualificação vocacional de seus colaboradores, ao investir pesado em treinamentos com o intuito de garantir um resultado positivo aos seus clientes. O sucesso nas vendas está totalmente ligado aos colaboradores (consultoras e consultores), os quais trabalham de forma direta com o consumidor, visto que a empresa atua no setor de venda direta. Acreditase que a quantidade de investimento em qualificação vocacional se dá justamente porque é por intermédio de seus colaboradores que a Natura consegue transmitir sua imagem.

Outro ponto alto do ano foi o crescimento de $28,5 \%$ no investimento em Educação e Aprendizagem, na operação Brasil. A Natura tem como política fornecer formação técnica para exercício das funções e apoiar o desenvolvimento pessoal e profissional de seus colaboradores. Em 2006, atingimos a média anual de 111 horas de treinamento por colaborador, muito superior à meta mínima de 40 horas (Relatório Anual de 2006, p. 51).

Nos RAs também são divulgados programas de voluntariado entre seus colaboradores, como forma de incentivar a comunidade a promover a inclusão social por meio da educação. Tais divulgações vinculam-se ao elemento Conscientização Social (Voluntariado).
Temos ainda um desafio interno de aproximar nossos colaboradores das comunidades do entorno. Nosso programa de voluntariado está voltado para esse fim. Em 2007, contamos com a participação de 77 colaboradores voluntários, que atuaram em instituições de ensino de Itapecerica da Serra e de Cajamar. (Relatório Anual de 2007, p. 36).

Outro aspecto de destaque é a importância que a organização demonstra com relação à ligação da marca com a responsabilidade social, a vinculação do nome ou da imagem com ações sociais, e a cultura organizacional Responsável.

Respaldada pelo reconhecimento vindo de consumidores e Consultoras, diretamente ligado aos valores assumidos e disseminados pela companhia, a Natura ostenta posição de destaque entre as marcas mais admiradas, [...] os consumidores destacam atributos como confiança, qualidade, criatividade e tecnologia, além de considerar a Natura uma empresa positivamente identificada com o Brasil [...], contribuindo para o desempenho dos negócios e impulsionando a força da marca Natura. (Relatório Anual de 2003, p. 29).

Entre os elementos não evidenciados durante o período analisado estão: Atividades com povos indígenas, projetos e ações de incentivos a práticas esportivas e projetos e ações de incentivo a práticas de lazer.

A Natura não desenvolve atividades com povos indígenas, mas reconhece e respeita as diferentes culturas e os direitos dos grupos socioculturais presentes no território nacional. (Relatório Anual de 2005, p. 102).

Tabela 2: Matriz de elementos de CI de natureza ambiental

\begin{tabular}{|l|l|c|c|c|c|c|c|}
\hline & \multicolumn{1}{|c|}{ Elementos de Capital Intelectual Ambiental } & $\mathbf{2 0 0 3}$ & $\mathbf{2 0 0 4}$ & $\mathbf{2 0 0 5}$ & $\mathbf{2 0 0 6}$ & $\mathbf{2 0 0 7}$ & $\mathbf{2 0 0 8}$ \\
\hline \multicolumn{1}{|c|}{ Competência do funcionário } & & & & & & \\
\hline 1 & Educação ou aprendizagem ambiental & 1 & 1 & 1 & 1 & 1 & 1 \\
\hline 2 & Conhecimento de práticas de responsabilidade ambiental & 1 & 1 & 1 & 1 & 1 & 1 \\
\hline 3 & $\begin{array}{l}\text { Competências relacionando o trabalho com a Responsabilidade } \\
\text { Ambiental }\end{array}$ & 1 & 1 & 1 & 1 & 1 & 1 \\
\hline 4 & Conscientização Ambiental & 1 & 1 & 1 & 1 & 1 & 1 \\
\hline$\quad$ Estrutura Interna & & & & & & \\
\hline 5 & Processos de Gestão Sustentáveis & 1 & 1 & 1 & 1 & 1 & 1 \\
\hline 6 & $\begin{array}{l}\text { Processos de Capitação e Minimização da emissão de resíduos } \\
\text { (Reciclagem) }\end{array}$ & 1 & 1 & 1 & 1 & 1 & 1 \\
\hline & $\quad$ & & & & & & \\
\hline 7 & Ligação da Marca com a Responsabilidade Ambiental & 1 & 1 & 1 & 1 & 1 & 1 \\
\hline 8 & Conscientização Ambiental dos Clientes & 1 & 1 & 1 & 1 & 1 & 1 \\
\hline 9 & Vinculação do nome ou da imagem com ações ambientais & 1 & 1 & 1 & 1 & 1 & 1 \\
\hline 10 & Integração parceira com a Comunidade & 1 & 1 & 1 & 1 & 1 & 1 \\
\hline 11 & Postura sustentável & 1 & 1 & 1 & 1 & 1 & 1 \\
\hline & Total & $\mathbf{1 1}$ & $\mathbf{1 1}$ & $\mathbf{1 1}$ & $\mathbf{1 1}$ & $\mathbf{1 1}$ & $\mathbf{1 1}$ \\
\hline
\end{tabular}

Fonte: Silva (2008). 


\subsubsection{Evidenciação dos elementos e das categorias do CI de natureza ambiental.}

A matriz de elementos ambientais também se encontra subdividida em três categorias que compõem o CI, distribuídas da seguinte forma: quatro elementos na Competência do Funcionário, dois elementos na Estrutura Interna e cinco elementos na Estrutura Externa, totalizando 11 elementos, conforme Tabela 2.

Gráfico 3 - Evidenciação dos elementos de CI de natureza ambiental por categoria

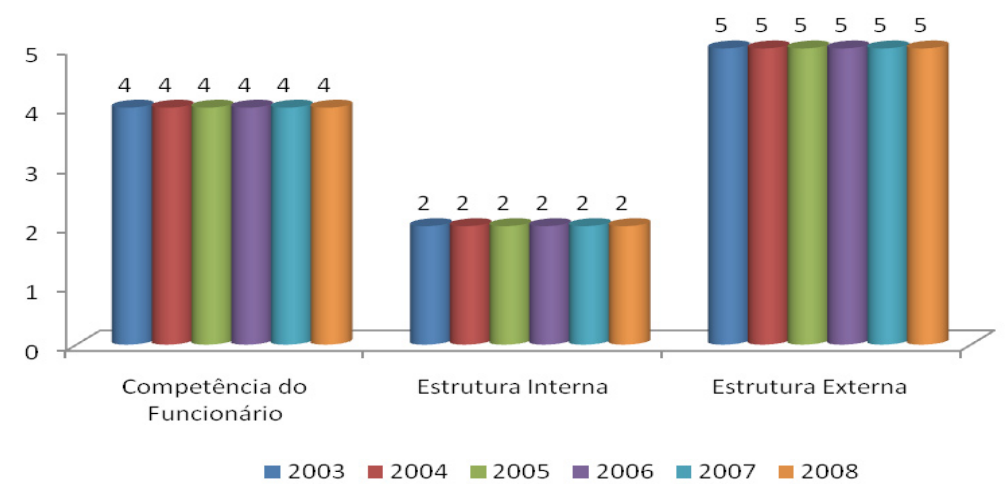

Fonte: Elaborado pela autora.

Observa-se no Gráfico 3 que todas as categorias obtiveram $100 \%$ dos elementos evidenciados, refletindo em um gráfico constante durante o período analisado.

Todos os elementos constantes nessa matriz foram evidenciados de forma narrativa. Isso demonstra o grau de preocupação da empresa pesquisada com relação às questões ambientais, visto que todos os elementos analisados foram evidenciados equitativamente ao longo dos seis anos, não sendo possível observar qualquer evolução, e sim obter uma evidência constante dos elementos, no Gráfico 4.
Esse resultado exibido no Gráfico 4 já era esperado, em razão da correlação que a organização faz da sua marca com suas ações ambientais. É forte a política de gestão da Natura com o meio ambiente, investindo em projetos ambiciosos.

A menção por parte da Natura com o fim de retratar a vinculação de sua Marca com a Responsabilidade Ambiental equivale ao elemento Ligação da Marca com a Responsabilidade Ambiental. Dessa forma, a empresa menciona, em seu RA, a existência desse elo entre a responsabilidade socioambiental e a sua marca.

Nosso desejo de disseminar o conceito de Bem Estar Bem e a visão de tornar a Natura uma marca de expressão mundial, identificada com a comunidade das pessoas que se comprometem com a construção de um mundo melhor através da melhor relação consigo mesmas, com o outro e com a natureza da qual fazem parte, exigem de nós ousadia e determinação. É com esse espírito que definimos a nossa estratégia de forte crescimento. (Relatório Anual de 2006, p.

9, grifo dos autores).

Com base nos resultados acima, confirma-se a mensagem que a presidência descreve em seus RAs: “A Natura, por seu comportamento empresarial, pela qualidade das relações que estabelece e por seus produtos e serviços, será uma marca de expressão mundial, identificada com a comunidade das pessoas que se comprometem com a construção de um mundo melhor através da melhor relação consigo mesmas, com o outro, com a Natureza da qual fazem parte, com o todo"

Gráfico 4 - Evidenciação dos elementos de CI de natureza ambiental

\section{Elementos de $\mathrm{Cl}$ de Natureza Ambiental}

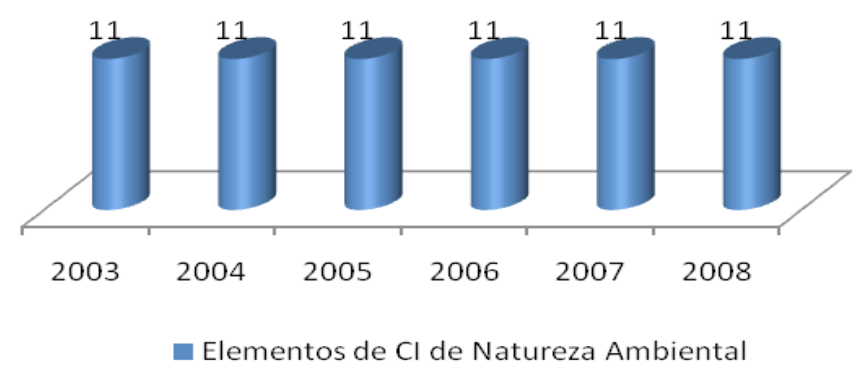

Fonte: Elaboração própria.
(Relatório Anual de 2006, p.13).

\subsection{Manifestações/depoimentos sobre os recursos intangíveis}

Ao analisar os RAs, foram encontrados depoimentos/ manifestações sobre os recursos intangíveis da empresa Natura Cosméticos.

O Quadro 01 apresenta o resultado da análise sobre essa perspectiva. 
Quadro 1: Depoimentos/Manifestações sobre os recursos intangíveis da empresa Natura ao longo dos anos

\begin{tabular}{|c|c|}
\hline ANO & $\begin{array}{c}\text { Quantidade de Depoimentos } \\
\text { no ano }\end{array}$ \\
\hline 2003 & 0 \\
\hline 2004 & 0 \\
\hline 2005 & 1 \\
\hline 2006 & 1 \\
\hline 2007 & 1 \\
\hline 2008 & 1 \\
\hline
\end{tabular}

Fonte: Elaboração própria.

O termo intangível começou a aparecer nos RAs a partir do ano 2005, principalmente nas Demonstrações Contábeis na forma de Notas Explicativas.

A pretexto de ilustrar os depoimentos/manifestações sobre os Recursos Intangíveis, serão reproduzidos, a seguir, trechos referentes às informações retiradas dos RAs da empresa Natura Cosméticos. Para facilitar a identificação dos recursos intangíveis nos exemplos abaixo, as indicações explícitas e implícitas são destacadas em negrito e itálico.

A primeira evidenciação do termo intangível acontece no RA de 2005, em que a empresa Natura reconhece a sua marca como seu maior bem intangível, demonstrando a preocupação da organização em manter sua marca bem estruturada, reconhecida mundialmente.

\begin{abstract}
A marca Natura é a tradução da essência da empresa e expressa os conceitos contidos em nossa Razão de Ser, em nossa Visão e em nossas Crenças. Maior ativo intangível da companhia, a marca Natura desempenha papel relevante na estratégia de internacionalização que estabelecemos. Por isso, cuidados especiais são dispensados ao seu fortalecimento e às iniciativas que a tornem conhecida em outros mercados. (Relatório Anual de 2005, p. 56).
\end{abstract}

O termo intangível também figura como depoimento no RA de 2007, quando a empresa Natura é reconhecida pela sua Gestão de Intangíveis, estando nesse quesito entre as 50 melhores empresas do Brasil, neste quesito.

Prêmios/Reconhecimentos: A empresa Natura recebeu o reconhecimento "Intangiveis do Brasil - PIB”, pela Revista Fator Brasil - Entre as 50 melhores empresas em Gestão de Intangíveis. (Relatório Anual de 2007, p. 11).
Percebe-se que a ênfase do termo intangível não é tão destacada nos RAs; por outro lado, esse termo está cada vez mais evidente de forma subjetiva, por meio da evidenciação de seus elementos, demonstrando ser um fator importante no grande desempenho que a empresa Natura vem conquistando a cada ano, com inúmeros prêmios e reconhecimentos pela eficiência do trabalho realizado durante toda a sua história.

\section{CONSIDERAÇÕES FINAIS}

O presente estudo analisou a evidenciação voluntária dos elementos de CI de natureza social e ambiental da empresa Natura Cosméticos, disponíveis nos Relatórios Anuais (RAs) do período entre 2003 e 2008. Para atingir seu objetivo, a pesquisa (i) extraiu dos RAs de 2003 a 2008 a evidenciação das informações relativas aos elementos de CI de natureza social e ambiental, por meio da técnica da análise de conteúdo; (ii) investigou a natureza da evidenciação do CI social e ambiental; (iii) analisou a evolução da evidenciação ao longo do período analisado (análise longitudinal); (iv) identificou os depoimentos/ manifestações sobre os recursos intangíveis.

A pesquisa aponta a predominância da evidenciação pela forma narrativa dos elementos de CI, com abordagem qualitativa. Os resultados confirmaram o esperado sobre a significância da evidenciação voluntária dos elementos de CI de natureza social e ambiental da empresa investigada. A Natura utiliza em sua gestão uma política de sustentabilidade, de equilíbrio entre o econômico, o social e o ambiental, vinculando, assim, sua marca às suas ações. Foi diagnosticada uma "falha" da empresa com relação à evolução das evidenciações dos elementos de natureza social, visto que ela não se mostrou preocupada em evidenciar elementos diferentes dos já evidenciados em RAs anteriores, mas, sim, em enfatizar cada vez mais os mesmos elementos antes referidos.

A Natura possui hoje uma das marcas mais valiosas do País, embora não tenha havido em seus RAs uma grande correlação entre seus elementos de CI e seu valor de mercado. A expressão intangível aparece com pouca ênfase em seus relatórios; por outro lado, ela está cada vez mais evidente de forma subjetiva, por intermédio dos elementos de CI evidenciados.

A revisão teórica apresentada possibilitou a reflexão sobre a perspectiva do conceito de Capital 
Intelectual pela ótica da Responsabilidade Socioambiental e a evidenciação voluntária dos elementos de CI, o que permitiu conciliar essas três abordagens diante da atual necessidade competitiva da empresa.

\subsection{Considerações sobre os resultados da Pesquisa}

Em relação aos objetivos inicialmente propostos pela pesquisa, apresenta-se as seguintes considerações:

* Identificar os elementos e as categorias do CI evidenciados voluntariamente nos RAs da empresa Natura Cosméticos, nos anos 2003, 2004, 2005, 2006, 2007 e 2008, por meio da análise de conteúdo.

Para atingir tal objetivo foi necessária a utilização de duas matrizes de elementos de CI propostas por Silva (2008): uma direcionada à abordagem social, contendo 27 elementos, e a outra contemplando a perspectiva ambiental, perfazendo um total de 11 elementos.

A partir desse momento foi possível perceber uma significativa evidenciação dos elementos de CI, tanto de natureza social como ambiental, apontando para a predominância da evidenciação de forma narrativa com abordagem qualitativa na empresa Natura Cosméticos, evidenciando, assim, uma média de 21 elementos/ ano de natureza social e 11 elementos/ano de natureza ambiental.

Foi possível perceber também que no relatório anual de 2008 houve uma redução das evidenciações de CI de natureza social. A empresa procurou abordar questões até então não abordadas em relatórios anteriores. Podese talvez caracterizar o relatório de 2008 como um fato isolado, por isso seria necessário/interessante a continuação desse estudo.

* Comparar os resultados da evidenciação do CI identificados longitudinalmente.

Observou-se, ao longo do período analisado, uma sutil variação quanto aos elementos de CI de natureza social, porém sem indício de uma evolução significativa. Com relação à evolução dos elementos de CI de natureza ambiental, foi observada uma constante evidenciação durante todo o período. Portanto, não foi possível obter tal evolução, pelo fato de terem sido evidenciados todos os 11 elementos propostos na matriz utilizada durante os seis anos analisados no trabalho.

$$
\begin{aligned}
& \text { * Coletar manifestações/depoimentos que } \\
& \text { reconhecem a presença dos recursos } \\
& \text { intangíveis. }
\end{aligned}
$$

Foi possível identificar que os depoimentos/ manifestações sobre os recursos intangíveis da empresa Natura foram evidenciados somente a partir do RA de 2005, mencionados principalmente nas Demonstrações Contábeis, em forma de Notas Explicativas.

5.2 Limitações da pesquisa e sugestões para futuras investigações

Em decorrência da limitação do período investigado nesta pesquisa, sugere-se dar continuidade ao estudo, pois o fato de não terem sido incluídos dados do período entre 2000 e 2002 pode ter "mascarado" uma possível evolução quanto à evidenciação dos elementos, além de se cogitar, também, que a análise do relatório do ano de 2008 possa ter sido um caso isolado diante da crise econômico-financeira que abalou as estruturas das grandes organizações.

\section{REFERÊNCIAS}

ANTUNES, M. T. P., MARTINS, E. Gerenciando o Capital Intelectual: uma proposta baseada na controladoria de grandes empresas brasileiras. Revista de Administração Eletrônica da UFRGS (READ), Porto Alegre, edição n 55, Vol. 13, Jan/Abri. 2007.

ASHLEY, Patrícia Almeida (coord.). Ética e Responsabilidade Social nos Negócios. $2^{\mathrm{a}}$ ed. São Paulo: Saraiva, 2005.

BARDIN, Laurence. Análise de Conteúdo. Lisboa: edições 70, 2004.

BEUREN, Ilse. Como elaborar trabalhos monográficos em contabilidade: Teoria e Prática. São Paulo: Atlas, 2003.

BONTIS, Nick. Intellectual capital: an exploratory study that develops measures and models. Management Decision. MCB University Press. V. 36, n. 2, pg. 63-76, 1998.

BOVESPA. Bolsa de Valores de São Paulo. Disponível em: $<$ http://www.bovespa.com.br/Principal.asp $>$. Acesso em 10 out. 2008.

BRENNAN, Niamh. Reporting intellectual capital in annual reports: Evidence from Ireland. Accounting, Auditing \& 
Accountability Journal. Bradford: 2001. Vol. 14, N. 4; p. 423437.

CARVALHO, Fernando Nitz de; ENSSLIN, Sandra Rolim; IGARASHI, Deisy Cristina Corrêa. Evidenciação Voluntária do Capital Intelectual no Contexto Brasileiro: Cotejamento com os Contextos Internacional e Australiano. In: ENANPAD, 30, 2006, Curitiba. Anais... Salvador: ANPAD, 2006. CDROM.

CHEN GOH, P.; PHENG LIM, K.. Disclosing intellectual capital in company annual reports: Evidence from Malaysia. Journal of Intellectual Capital. Bradford: 2004. Vol. 5, N. 3; p. $500-511$

CUNHA, J. H. C. A contabilidade e o real valor das empresas foco no capital intelectual. In: Congresso USP de Controladoria e Contabilidade. 6., 2006, São Paulo. Anais... São Paulo: FEA/ USP, 2006. CD-ROM

EDVINSSON, Leif. MALONE, Michael S. Capital Intelectual: Descobrindo o valor real de sua empresa pela identificação de seus valores internos. São Paulo: Makron Books, 1998.

ENSSLIN, S. R. CARVALHO, F. N.; Voluntary disclosure of intellectual capital in the Brazilian context: an investigation informed by the international context. International Journal Accounting, Auditing and Performance Evaluation, Vol. 4, pg. 478-500, 2007.

FACHIN, Odília. Fundamentos de Metodologia. $4^{\mathrm{a}}$ edição. São Paulo: Saraiva, 2005.

FILHO,FranciscoFrancílioDouradodaSilva. Responsabilidade Socioambiental como Paradigma Contemporâneo. In: Encontro Nacional Sobre Gestão Empresarial e Meio Ambiente - IX Engema. Curitiba, 2007.

GALLON; A. V.; LYRIO, M. V. L.; ENSSLIN, S. R. Gerenciamento do Capital Intelectual de uma EBT Incubada: a Contribuição da Metodologia Multicritério de Apoio à Decisão Construtivista. In: ENANPAD, 32., 2008, Rio de Janeiro. Anais... Rio de Janeiro: ANPAD, 2008. CD-ROM.

GUTHRIE, J.; PETTY, R.; FERRIER, F.; WELLS, R. There is no accounting for intellectual capital in Australia: review of annual reporting practices and internal measurement of intangibles within Australian organization. International Symposium of Measuring and Reporting Intellectual Capital. Amsterdam, 1999.

Instituto Ethos. Disponível em: <http://www.ethos.org.br> Acesso em: 10 out. 2008.

IUDÍCIBUS, S. Teoria da contabilidade. $7^{\mathrm{a}}$ ed. Atlas, São Paulo: 2004.

IUDÍCIBUS, S.; LOPES, A. B. Teoria Avançada da Contabilidade. Atlas, São Paulo: 2004.

KAPLAN, Robert S. NORTON, David P. Mapas Estratégicos: Convertendo ativos intangíveis em resultados tangíveis. Rio de
Janeiro: Campus, 2004

KLEIN, David A. A gestão estratégica do capital intelectual: Recursos para a economia baseada em conhecimento. Rio de Janeiro: Qualitymark, 1998.

LOPES, A. B.; MARTINS, E. Teoria da Contabilidade: uma nova abordagem. Atlas, São Paulo: 2005.

MOUTISEN, J., BUKH, P. N., MARR, B. A Reporting Perspective Intellectual Capital. Cap 5. in MARR, B., Perspectives on Intellectual Capital: multidisciplinary insights into management, measurement and reporting. Elsevir, 2005.

PIACENTINI, N. Evidenciação contábil voluntária: uma análise da prática adotada por companhias abertas brasileiras. Dissertação (Mestrado em Ciências Contábeis). 2004. 132 f. Universidade do vale do Rio dos Sinos (Unisinos). São Leopoldo, 2004

PUGLISI, M.L.; FRANCO, B. Análise de conteúdo. 2. ed. Brasília: Líber Livro, 2005.

REINA, D.; ENSSLIN, S. R. Evidenciação Voluntária do Capital Intelectual nos Relatórios da Administração em Empresas do Novo Mercado no ano de 2006. In: CONTECSI - Congresso Internacional de Gestão de Tecnologia e Sistemas de Informação. 5., 2008, São Paulo. Anais... São Paulo: FEA USP, 2008. CD-ROM.

REZENDE, Yara. Informações para negócios: os novos agentes do conhecimento e a gestão do capital intelectual. Caderno de Pesquisas em Administração, São Paulo, V. 8, n 1, Jan/Mar. 2001.

RICHARDSON, R. J. Pesquisa Social - Métodos e Técnicas. $3^{\text {a }}$ ed. Atlas, São Paulo: 1999.

ROCHA, S.; ARRUDA, C. Aplicação de ferramenta de medição de capital intelectual em uma empresa industrial In: ENANPAD, 29., 2005, Brasília. Anais... Rio de Janeiro: ANPAD, 2005. CD-ROM.

SILVA, Harley Almeida Soares da. Evidenciação do Capital Intelectual de Natureza Social e Ambiental: Estudo nos Relatórios Anuais e nos Sites das Empresas Listadas no Programa "Em Boa Companhia" da Bovespa. 2008. 129f. Monografia (Graduação em Ciências Contábeis) - Curso de Graduação em Ciências Contábeis - Universidade Federal de Santa Catarina, Florianópolis.

SVEIBY, K. E. The new organizational wealth-management and measuring knowledge-based assets. São Francisco: Berrtt Koehler Publishers Inc, 1997.

ZANINI, F. A. M.; CALVO, L. C. Midiendo el Capital Intelectual de las Empresas: Propuesta de dos Proxies. BASE - Revista de Administração e Contabilidade da Unisinos. São Leopoldo. V. 3, n. 3, ed. Set/Dez 2006. 